\title{
Can Mohalla Clinics be a Catalyst for Ayushman Bharat Pradhan Mantri Jan Arogya Yojna to achieve Universal Health Coverage in India?
}

BACKGROUND: Expenditure on health sector in India is one of the lowest public health expenditures in the world at just over 1\% of GDP, with substantial disparities in population, infrastructure, availability and provision of services that define the Indian health care system. In a reform of Indian health systems approved by the Indian Government in March 2018, Ayushman Bharat Pradhan Mantri Jan Arogya Yojana (AB-PMJAY) was launched on 23rd September, 2018 to provide financial health insurance coverage of Rs. 5 lakhs per family per year for secondary and tertiary care hospitalizations to more than 10.74 million poor families that form the bottom $40 \%$ of population in India. OBJECTIVES: The objective of this paper is to discuss and analyze the benefits and weaknesses of the AB-PMJAY model and investigating the position that these clinics can play in (I) improving the provision of urban health facilities (II) resolving health inequities (III) and enhancing primary health care.

MATERIALS AND METHOD: The authors explored different databases. Government portals, research publications on AB-PMJAY and Mohalla clinics (MC) to do in-depth analysis of various parameters.

RESULTS: Although there are significant obstacles to the programme, by building impetus for program reform, AB-PMJAY offers an opportunity for the nation to resolve long-standing and ingrained shortcomings in governance, quality control and stewardship, and to accelerate India's development towards the stated UHC supply goal. The main achievement of these facilities in the last 18 months has been to introduce wellness to civic and political dialogue.

CONCLUSION: Mohalla Clinics can prove as a major catalyst for Ayushman Bharat Pradhan Mantri Jan Arogya Yojna for health reforms and progress towards universal health coverage in India.

KEYWORDS: Mohalla Clinics, Primary Health Care, Universal Health Coverage, AB- PMJAY

\section{INTRODUCTION}

The protection of basic human rights is essential to the "right to health." Yet wellbeing will also be remembered as a constitutional right in our Constitution. Several papers and several decisions of the Honorable Supreme Court lay down ample requirements for "access to health" to people in compliance with the values of the Directive, but do not include it as a basic right, including the right to pursue substantive remedy if health / care is withheld. ${ }^{1}$

In India, for financial reasons about $6 \%$ do not receive health coverage $e^{2}$ and, often experience is financially debilitating and impoverishing for those who have. After the report of the Bhore Committee (1946), central/state governments have made efforts to provide health care through the country's network of three tiers of health institutions and separate national health programmes. Certain milestones include success stories of smallpox eradication, dracunculiasis or regional leprosy removal, neonatal tetanus, controls against malaria / other vector-borne diseases and reduction of maternal and child mortality.
Household out-of-pocket expense in our nation is $67 \%$ of overall health spending ${ }^{3} 2^{\text {th }}$ among the supreme of 191 nations $^{4}$ and 6th among 50 low-middle-income nations. ${ }^{5}$ Health is a neglected issue and government should not be deceptive. It was never a priority for either faction or usually a casual last-minute presence in the voting demonstrations. It is also inviting that vital steps are taken in recent years to resolve this problem - the 2017 National Health Policy (NHP) and the 2018 Ayushman Bharat Yojna, both critical for achieving the Universal Health Coverage (UHC) both a World Health Day priority and a pledge from India to the Sustainable Development Goals (SDGs). In the past ten years, the Indian health programme, including measles, Jaws, Maternal and Neonatal Tetanus prevention, had some success. ${ }^{6}$

This leads to overcrowding, excessive turnarounds, inadequate level of care and deception with public health programmes. In this experience, people, including the poorest quintiles residents, find too many issues in public health, 'vote on their feet' and 
visit either unqualified providers or private providers, and not waste much time in travel without a service warranty, waiting for hours to be seen by their doctor and then wasting on medication and diagnostics. ${ }^{7,8}$ The situation seems to have changed somewhat over the last 10-15 years, but there is still a lot to be desired. As provided by the Government, India's National Health Mission has contributed to increased attention to health, although not to the extent that one would have liked. Among state-level health service delivery initiatives, the Mohalla or Community Clinics of Delhi State, India, have received a great deal of national and international attention and interest - mostly favorable - from media and health experts alike. ${ }^{8,9} \mathrm{~A}$ number of Indian states, all governed by political parties other than those in power in Delhi, have shown interest in establishing similar clinics. ${ }^{10}$

This article has been written to understand the design and evolution of Mohalla clinics along with ABPMJAY; evaluating and examining the strengths and shortcomings of AB-PMJAY and proposing a wider vision for the advancement of universal health coverage (UHC) in contrast with Mohalla clinics, Delhi, India.

\section{MATERIAL AND METHODS}

We thoroughly explored the National Library of Medicine's PubMed database and Google Scholar by using free text words like Mohalla Clinics, Primary Health Care, Universal Health Coverage, Ayushman Bharat Pradhan Mantri Arogya Yojana, AB- PMJAY. Around 27 full text articles and abstracts were selected.

Ayushman Bharat Yojna: In 2018 the budget announced on Ayushman Bharat on behalf upon launching of hospitals and wellness centres (HWCs) and an ambitious national health care security (NHPS) two big measures for India 2022. ${ }^{11}$

Health \& Wellness Centres Scheme: A wider and more inclusive programme of primary health services will be provided at ground level by updating sub centres (SCs) to health \& wellness centres (HWCs). Emphasis has now been extended from preventive part to primordial part, curative and palliative treatment. Up gradation of SC or HWC will include a point of treatment, a fitness room for yoga and naturopathy, physiotherapy and community sessions and a consulting space with full anonymity, free diagnostics and pharmacy, telemedicine services and a waiting area for more than 30 citizens. The HWC programme plan is also comprehensive and includes specific otolaryngology and ophthalmic disorders, oral health, psychiatric illness and palliative wellbeing, emergency medical treatment, the control of communicable as well as non-communicable diseases, general OPDs development, parental, neonatal, child and teenage health facilities. It also involves the development of online health records in favor of a comprehensive IT programme.

Ayushman Bharat National Health Protection Scheme (ABNHPS): This flagship, scheme is funded centrally, seeks to provide annual health coverage of up to Rs. 5 lakh to poor 10 crore families (approximately 50 crore people $-40 \%$ of the country's population) based on the Socio Economic and Caste Census database. This framework has also been in operation since 2020 and a huge push has been initiated in order to create demand, which includes campaigns on health education, community mobilization and gram sabhas recognition and information. On April $30^{\text {th }}$, Ayushman Bharat Divas is observed when each rural beneficiary is not only briefed and told about the programme but is also reported for each deserving recipient by data (mobile phone, ration card numbers, change of family status, etc.). Each one of them will be linked with a HWC to ensure that no one is deprived of the scheme benefits. NHPS will be funded by existing federally financed programmes such as Rashtriya Swasthya Bima Yojana (RSBY) and the Senior Citizen Health Insurance Scheme. The scheme, called Modicare, will be the first state-funded health insurance scheme and a major leap forward in UHC, the OOPE and covering about $40 \%$ of vulnerable people from high health-care expenses. ${ }^{12}$

Health Systems in Delhi, India: Delhi is a city-state in India with a population of 1.68 crores (or 16.8 million) in 2011, with 97.5 per cent of the population living in urban areas, $1483 \mathrm{~km}^{2}$ of geographical area, and a population density of 11.297 crores (range 3800$\left.37.346 / \mathrm{km}^{2}\right)$. This has about 18 lakh (1.8 million) or 11 percent of the people residing in the slums ${ }^{13}$ and a significant proportion of this population has migrated from different parts of the world. Delhi is the most populated urban agglomeration in India and the third largest metropolitan area in the world. Twelve separate organizations offer health services in Delhi (if three municipal corporations are counted separately, the number will be fourteen). Delhi has different 
outlets open for the quantity of health centres. As on 31st March 2014, there were 95 Hospitals, 2 Primary Health Centres, 1389 Dispensaries, 267 Maternity Homes \& Sub Centres, 19 Polyclinics, 973 Nursing Homes, 27 Special Clinics existing in Delhi. ${ }^{8}$ In addition, 15 government-run medical colleges were founded in the allopathic medicine system. The people's pulse is sensed by politicians and leaders; it is one of the services which really is common to the public. The healthcare systems assessed these clinics perform well, including budget allocation for the establishment of 1,00o such clinics (in INR 20 lakh) in terms of accessibility, equity, feasibility, responsiveness, and financial protection. INR 200 crore (approximately USD 30 million) was spent to develop 1000 such clinics. That accounted for around four percent (i.e. INR 5259 crores or $\$ 784$ million) of the Delhi government total health budget.

\section{MOHALLA CLINICS:}

The Concept and Design: The Mohalla Clinic Initiative was launched by the Delhi Government in July 2015, with one clinic located in the slums. ${ }^{14,15}$ The idea stemmed from the success of mobile vans or mobile medical units (MMUs). It was then complemented by the requirement of the top political leadership to fulfil the electoral promise and commitment to strengthen health systems rather than to provide ad hoc solutions.

Evolution of Mohalla Clinics (July 2015-December 2019): The first Delhi Mohalla clinic was opened in Peeragarhi community in West Delhi on $19^{\text {th }}$ July 2015. It took another 9 months to set up another 100 clinics. By December 2016, a total of 106 clinics were founded across all 11 districts and in 55 of the total 70 state assemblies. ${ }^{14}$ The first clinic was set up in the Portacabin system in government property. Another attempt to expedite the process by opening these clinics in government schools met the administrative hurdle and could not materialize until 31 December 2016, due to pending approval by the authorities. ${ }^{16}$ Most clinics started in the beginning of 2016 and soon afterward became common in the community. An official Delhi Government release stated that almost 8oo,ooo people in July 2016 were provided health services, and 43,000 tests were performed in five months. ${ }^{17}$

On average, 70-100 patients per day have been treated in each facility. In September-October 2016, when Delhi saw an epidemic of Dengue and Chikungunya diseases and when patients were overloaded at health facilities, patients in the Mohalla clinics became a key entry point for examining and laboratory testing. Delhi Government undisclosed estimates have indicated that 40 to 50 per cent of patients in these clinics attended public health services for the first time. Many unskilled doctors of clinics at Mohalla Clinics recognize the decreased pressure of patients. It is generally accepted that these centres provide greater access, but this must be studied and more systematically registered, to health services by qualified professionals to the poorest of the poor. Several changes/improvements/mid-term design corrections have been made, all to make these clinics friendly to patients.

Certain decisions, such as private sector engagement, healthcare provision in three or four steps and the reduction of government agencies consumer fees, are directly related to effective usage and access of healthcare, which makes them affordable and decreases the burden in buckets.

\section{RESULT}

Critical areas under health and wellness centre scheme: Budget allocated under HWC scheme is Rs. 1200 crores for upgradation of $1,50,000$ SC. ${ }^{18}$ The result is Rs. 8o,ooo a year per SC. If it is an annual award, the logistics, manpower and overhaul needed to fulfil the extended spectrum of programmes are also quite inadequate. In fact, most of the community health centres are not even eligible for HWC services (CHCs). Owing to a massive shortfall of physicians and other CHC assistance ${ }^{19}$, upgrading SCs to HWCs without matching referral setup can be counterproductive.

Critical areas under Ayushman Bharat National Health Protection Scheme: NHP 2017 is aimed at guaranteeing the UHC and strengthening the confidence in the public health system by strengthening and extending its programmes. The goal of this programme is to lift government health spending by 2025 from 1.15 to 2.5 per cent as a percentage of the gross national product..$^{20}$ This means almost doubling the budgetary allocation in the next 6-7 years. It seems impossible, considering that 20182019 budgetary allocation (Rs. 52,800 crores) is only $2.4 \%$ higher over the last year. ${ }^{19}$ This is in contrast to a similar Rashtriya Swasthya Suraksha Yojna proposed in Budget 2016 with an allocation of Rs 1,500 crore, to provide an annual cover of Rs. 1 lakh per economically weaker household. ${ }^{21}$ This gap is proposed to be 
bridged by matching contribution from the state governments. It is to be noted that this premium is sure to go up to Rs. 5,00o or more in future; depending on the maturity of the scheme and pay outs in the long run. Single most important reason for no availability of health services (especially curative) in remote areas is the shortage of workforce at different levels. Situation review of current rural health services shows that the scarcity of health facilities rises as the quality of care increases. India's entire rural public health gap measured by rural population (Census 2011) for rural areas is $19 \%$; primary health centres (PHC) are $22 \%$; and CHCs $30 \%$. Rural public health facilities are $22 \%$ in India. ${ }^{19}$ This shortfall is compounded by the shocking shortage for specialist doctors (around 80\%) - essential for secondary/tertiary care.

\section{DISCUSSION}

Mohalla clinics are believed to be yet another centre of that kind. However, well-conceived considerations in design cause Mohalla clinics to differentiate them from traditional health care. However, the constructive approach to the area of harmonization/integration of activities and the convergence/coordination of different kinds of health centres managed by distinct entities, which are complicated, time-consuming and daunting for ordinary people, is one that must be addressed at various healthcare institutions. The Delhi State's health services are supplied by almost 25 different forms of health facilities.

In Delhi, several advancements have been made to enhance the quality of healthcare facilities, including paying doctors for treatment, leasing of premises for Mohalla Clinics, and flexible and variable clinic hours. A number of additional systems are now in operation, i.e. the successful use for staffing selected facilities of trainees and post-graduate students from medical schools. In these hospitals and other health centres, use of computer technology should be handled as optimally as possible.

The unsuccessful effort to create clinics in schools should not be deterrent, and the government is continuing to investigate options to strengthen student health care through such clinics. With nearly 40 lakh students ${ }^{22}$ in schools across Delhi, an effective linkage in between Mohalla clinics and schools could be a game changer for the health of younger generations.
In order to achieve the systemic advancement of healthcare, legislative policies and proposed government reforms need to be speeded up. Mohalla clinics could prove an important platform for the promotion and strengthening of universal healthcare (UHC) coverage in India.

Lastly, much study in these clinics is unsystematic and experiential. One is the need to document and learn from these clinics in depth, backed by evidence collected through the clinical processes. Secondly, if the clinics are too many and ample time to set up a curriculum, it is valuable to carry out an exhaustive, systematic and objective review of the clinics and other progress in order to benefit from them and make corrections. Such clinics have raised the standard of healthcare in political discourses, a partial outcome already, but still far from the Bijli-Sadak-Pani (BSP) situation almost 15 years ago.

It is likely that with more similar initiatives on health (and education) by a growing number of states in India, Swachchata-Swashthya-Shiksha-SafaaiSaamaajickshetra (cleanness-economic-educationhealth-health-social sector or CHESS, in short) will become the next electoral agenda, replacing B-S-P. It might be the CHESS, the Indian people wouldn't mind if politicians began to play more often.

\section{CONCLUSION}

Mohalla clinics provide personal health care (curative and diagnostic), but the advancement of $\mathrm{PHC}$ requires a holistic approach and stronger dedication to neighbourhood and/or public health services through oriented interventions. While some people want mohalla clinics to be another kind of health centre, the concept has the potential to inspire improvement of the Indian health system. It is proposed that most of the current infrastructure in the health sector, such as pharmacies, and the incorporation of the operation of such hospitals into other existing/planned systems such as UPHC under NUHM can be built in addition to building new facilities. In reality, success and changes in the health sector would balance this initiative. As practitioners of community medicine, we would like to say that NHPS was a misnomer. It does not offer health insurance but only medical attention, and patients are often mainly provided in private/corporate hospitals. Until the governance structure is changed, the desired result on the currently exceptionally large budget out of pocket 
spending will not be met. Allocations are not appropriate for both NHPS and HWC schemes and where there are any signs of RSBY vulnerabilities; the NHPS is likely to lead to undue care or unwanted interference. Therefore the premium level is expected to rise if the device is used (misused, overused/abused). In order to ensure the feasibility of this system, well-designed standardised protocols and guidelines should be required on admission, examination, diagnosis, reference, documentation and good quality control. The Mohalla Clinics are a positive beginning; however, the greatest success will be when: (1) it enhances the need for more countrywide primary healthcare (2) health services are able to influence electoral outcomes and (3) catalyze efforts in, for example, the growth of health systems. These measures are critical as India continues to make progress towards universal health coverage. In this amazing journey, Mohalla clinics can prove such a small but significant factor.

\section{REFERENCES}

1. A Study of Constitutional and Judicial Attitude Right to Health in India 2010. (Online PDF). Available from:

https://shodhganga.inflibnet.ac.in/bitstream/10603/4 0578/10/13 chapter4.pdf. [Last Accessed on $16^{\text {th }}$ November, 2020]

2. Bakshi H, Sharma R, Kumar P. Ayushman bharat initiative (2018): What we stand to gain or lose!. Indian J Community Med 2018;43:63-6. https://doi.org/10.4103/ijcm.IJCM_96_18

3. Mohanty SK, Kastor A. Out-of-pocket expenditure and catastrophic health spending on maternal care in public and private health centres in India: a comparative study of pre and post national health mission period. Health Econ Rev. 2017; 7(1):31. https://doi.org/10.1186/s13561-017-0167-1

4. WHO. Global action plan on physical activity 20182030: more active people for a healthier world. (Online PDF).

Available

from: https://apps.who.int/iris/bitstream/handle/10665/272 722/9789241514187-eng.pdf?ua $=1$. [Last Accessed on $15^{\text {th }}$ November, 2020]

5. Vivek V. Indians Sixth Biggest Private Spenders on Health Among Low-Middle Income Nations. (Online Article). Available from: https://www.indiaspend.com/indians-sixth-biggestprivate-spenders-on-health-among-low-middleincome-nations-78476/. [Last Accessed on $15^{\text {th }}$ November, 2020]
6. Lahariya C. 'Shining a light on invisibles': Specific learning disabilities and Universal Health Coverage. J Postgrad Med 2019;65:132-3. https://doi.org/10.4103/jpgm.JPGM_95_19

7. Lahariya C. Mohalla Clinics of Delhi, India: Could these become platform to strengthen primary healthcare?. J Family Med Prim Care. 2017;6(1):1-10. https://doi.org/10.4103/jfmpc.jfmpc_29_17.

8. PTI. Delhi gets first 'Aam Aadmi Clinic', CM Kejriwal says 1000 more in line. (Online Article). Available from: https://indianexpress.com/article/cities/delhi/delhigets-first-aam-aadmi-clinic-cm-kejriwal-says-1000more-in-line/. [Last Accessed on $15^{\text {th }}$ November, 2020] 9. Pomeroy M, Shankland A, Poskitt A, Bandyopadhyay KK, Tandon R. Civil Society, BRICS and International Development Cooperation: Perspectives from India, South Africa and Brazil. The BRICS in International Development: Springer; 2016. p. 169-206.

10. Eye on polls, Gujarat govt to set up 'mohalla clinics' in 4 cities: Indian Express; 2016 [Available from: https://indianexpress.com/article/cities/ahmedabad/ eye-on-polls-gujarat-govt-to-set-up-mohalla-clinicsin-4-cities-3069359/.

11. Panda PK. Ayushman Bharat: Challenges and Way Forward. Jaipuria International Journal of Management Research. 2019;5(2):89.

12. Pareek M. Ayushman Bharat-national health protection mission a way towards universal health cover by reaching the bottom of the pyramid-To be a game changer or non-starter. international journal of advanced and innovative research. 2018;7(7):1-10.

13. Sindhwani R, Goyal P. Assessment of trafficgenerated gaseous and particulate matter emissions and trends over Delhi (2000-2010). Atmospheric Pollution Research. 2014;5(3):438-6.

14. Mohalla Clinics: Govt. of India; 2016. Online PDF. Available from: https://www.dshm.delhi.gov.in/pdf/AamAadmiMohall aClinics.pdf. [Last Accessed on $16^{\text {th }}$ November, 2020] 15. Lahariya C. Health \& Wellness Centers to Strengthen Primary Health Care in India: Concept, Progress and Ways Forward. Indian J Pediatr. 2020;87(11):916-929. https://doi.org/10.1007/s12098o20-03359-z.

16. Lahariya C. 'Ayushman Bharat'program and universal health coverage in India. Indian Pediatr. 2018;55(6):495-506.

17. Hindustan Times. Eight lakh treated in five months at Delhi mohalla clinics. (Online Article). Available from: https://www.hindustantimes.com/delhi/eight-lakh- 
treated-in-five-months-at-delhi-mohalla-clinics/storyKQl2baCrI5lz8TS3ZmuziN.html. [Last

Accessed on $16^{\text {th }}$ November, 2020]

18. National Health Profile 2015. Central Bureau of Health Intelligence. Nirman Bhawan, New Delhi: MoHFW, Govt. of India: Government of India; 2018. (Online PDF). Available from: http://www.cbhidghs.nic.in/WriteReadData/l892s/Bef ore\%2oChapter1.pdf. [Last Accessed on $16^{\text {th }}$ November, 2020]

19. Reserve Bank of India. State Finances a Study of Budgets Of 2017-18 And 2018-19. (Online PDF). Available from: https://smartnet.niua.org/sites/default/files/resources Losf201718 full6ee17cfbd8004287aocd 4fdbo632afe8.pdf . [Last Accessed on $16^{\text {th }}$ November, 2020] 20. Berman P, Bhawalkar M, Jha R. Government financing of health care in India since 2005: What was achieved, what was not and why?. (Online PDF). Available from: https://cdn1.sph.harvard.edu/wpcontent/uploads/sites/2031/2017/o1/Governmentfinancing-of-health-care-in-India-since-2005.pdf. [Last Accessed on $16^{\text {th }}$ November, 2020]

21. Chowdhury S, Mukherjee S. Can Ayushman Bharat National Health Protection Mission protect health of India's Poor?.(Online Article). Available from: http://idsk.edu.in/wp-content/uploads/2019/o1/OP64.pdf. [Last Accessed on 16th November, 2020] 22. Ravi S, Ahluwalia R, Bergkvist S. Health and morbidity in India (2004-2014). Brookings India (2016). (Online PDF). Available from: https://www.brookings.edu/wpcontent/uploads/2016/12/201612 health-andmorbidity.pdf. [Last Accessed on $17^{\text {th }}$ November, 2020]

1. Dept. of Public Health, School of Allied Health Sciences, Delhi Pharmaceutical Sciences and Research University (DPSRU), Govt.

of NCT Delhi, New Delhi - 110017 [ORCID ID: https://orcid.org/oooo-0o03-4856-9012, Mr. Debraj Mukhopadhyay]

2. Dept. of Public Health, School of Allied Health Sciences, Macquarie University, Sydney, Australia

3. Dept. of Public Health, Torrens University, Adelaide City Centre, Sydney, Australia

4. Dept. of Public Health, Indian Institute of Public Health (IIPH), Gandhinagar, Gujrat - 382042 